\title{
Integrating Entrepreneurial Mind-set into First-Year Engineering Curricu- lum through Active Learning Exercises
}

\section{Dr. Chad S. Korach, University of Mount Union}

Chad Korach is an Associate Professor of Mechanical Engineering and Director of Engineering at the University of Mount Union in Alliance, Ohio.

\section{Dr. Joshua Gargac, University of Mount Union}

Joshua Gargac is an assistant professor of mechanical engineering at the University of Mount Union in Alliance, $\mathrm{OH}$, where he advises the mechanical engineering senior capstone projects and SAE Baja team. In addition, Dr. Gargac teaches first-year engineering courses, computer-aided design, kinematics and dynamics of machinery, and manufacturing science. He received his BSME from Ohio Northern University and a PhD in Bioengineering from the University of Notre Dame. Current interests include bone tissue mechanics, engineering pedagogy, and robotic football. 


\title{
Integrating Entrepreneurial Mindset into First-Year Engineering Curriculum through Active Learning Exercises
}

\begin{abstract}
Entrepreneurial principles have been an increasing focus of undergraduate engineering curricula at multiple levels of integration. Here, the Entrepreneurial Mindset (EM) has been integrated into a first-year, general engineering course using active learning exercises to develop creative problem solving and critical thinking. These exercises were introduced periodically within the course schedule to complement the existing learning objectives and goals of the introductory course. Since the course culminated with a 7-week team design project, team-based exercises were used to enable team-building throughout the semester and to expose students to different decision-making styles and team dynamics. Similarly, as the students were introduced to the engineering design process, EM exercises were incorporated to explore problem definitions, open verses constrained problems, and prototyping. Exercises also explored other beneficial EM concepts including iteration in problem solutions, learning from failures, sales pitches, system scaling, and taking action versus over-planning. Typically, one active learning exercise was incorporated into each course meeting throughout the semester. Students anecdotally responded with positive enthusiasm to the activities with interest in pursuing entrepreneurship in addition to engineering. Overall, the integration of the EM activities equipped the course instructors with useful tools to engage the students in the course content, generate excitement for a future in engineering, and develop EM skills beneficial for a successful career.
\end{abstract}

\section{Introduction}

The University of Mount Union utilizes a two-semester first-year engineering sequence. One of the four pillars of the Mount Union Engineering programs is the integration of business and entrepreneurship into the curriculum. This paper describes the efforts made to integrate the Entrepreneurial Mindset (EM) into the fall semester first-year engineering course. The course is a 2-credit hour semester long course that meets once a week for 100 minutes. Serving as an introduction the engineering profession, the course presents active-learning sessions on each of the five engineering disciplines offered at Mount Union: Biomedical, Civil, Computer, Electrical, and Mechanical Engineering. A 7-week design project focused on buoyancy [1] is also a part of the course. Starting in the Fall 2017 semester and continued in 2018, EM activelearning exercises were integrated into the course to teach the EM. Prior to 2017 only one active learning-based activity was integrated into the course.

Teaching EM in first year engineering courses has been a popular topic in engineering education [2]. The goal of this paper is to describe how EM was introduced in a first-year course explicitly through active-learning based exercises from the Play, Empathy, Creation, Experimentation, and Reflection practice-based approach of teaching entrepreneurship from Babson College [3]. The goal here is to remain active in teaching the EM, as the concepts and practices are new to the freshman engineering students. The objective was to make the activities not only fun, but 
entertaining and ultimately educational. The paper is structured to explain the eight active exercises first then to provide the assessment tool used and data collected.

\section{Entrepreneurial Mindset Exercises}

There were eight activities used throughout the semester to introduce the EM in the freshman engineering course. The activities were active-learning based and designed to have students work in teams and to move around the classroom instead of remaining in a traditional seated lecture. Outcomes of the activities were focused on creative problem solving skills and critical thinking skills. Many of the activities were from traditional entrepreneurship and team-building focuses and have been adapted to have an engineering focus. As follows each activity is briefly described with anticipated outcomes.

Puzzle-Quilt

This is an active exercise which involves multiple rooms and team structures and was adapted from "Puzzles and Quilts" [3]. The exercise involves students starting off in teams of 4-5 students which are randomly assigned. Each team is provided a 300 piece puzzle with the instructions that the goal of the exercise is to complete the puzzle in the least amount of time. One student is removed from each team every 4-5 minutes and taken to a second room containing a table of random 5" 5 " pieces of cloth. Here the goal is to create the best quilt. The first set of students are individual quilt leaders. Each student entering the second room takes six cloth squares and chooses which quilt leader they would like to join. The activity concludes when all team members working on the puzzles are in the second room and have contributed to creating the quilts.

This exercise creates an exciting dynamic and focuses on exposing students to constrained and unconstrained designs in one exercise. The debrief is focused on discussing the students' preferences on which activity they preferred (Puzzle versus Quilt), how engineering design uses both types of thinking at different times, and the EM concept of taking action when in an uncertain environment.

\section{Spaghetti Tower}

This active exercise was adapted from the "Marshmallow Tower" [3] and was originally developed by Tom Wujec [4]. The exercise is team-based with students in teams of $\sim 4-5$. The students are given a bag of materials which includes: 20 pieces of uncooked spaghetti, 1 yard of string, 1 yard of masking tape, and 1 standard size marshmallow. The goal is to build a freestanding tower out of the given materials with the marshmallow at the top in 18 mins. The team which has the highest distance from the table top to the top of the marshmallow wins.

The exercise is great for team-building and is dynamic in that a time constraint exists with a very specific end goal. How the teams reach that goal is a key takeaway. The outcome of the exercise is dependent on the discipline demographics and age group which are taking part in it. The debrief focuses on the pitfalls of over planning, the importance of trail and error 
experimentation, and learning from failure. Engineering students do quite well with this exercise and it is important for them to learn the team dynamic skills and that failure is okay, the actions you take with the failures is what is important for improving designs.

\section{Crossing the River}

This is an active exercise attributed to Daniel Raviv [5] which is best performed outdoors, preferably on a soft surface. We have been performing the exercise on a sand volleyball court in the early part of the fall semester when the weather is still hospitable in northern climates. The exercise involves breaking the class into two teams with $\sim 10$ students in each team. The students are given a folding step stool, a 24 foot rope, and two 4 foot $2 \times 4$ pieces of lumbar. The goal is for teams to move all team members from one side of the volleyball court (30 feet) to the other without touching the surface, in this case the sand, but metaphorically the river water, hence the exercise title. Students that touch the imaginary water must go back to the starting side of the imaginary riverbank and try again. The first team to get all members across is the winner.

The debrief for the exercise focuses on the importance of creative problem solving, teamwork, and leadership. Teams that excel at this activity are engaged with each other, clearly communicate their ideas with one another, and are open to different ideas. Many of the solutions involves students working in pairs or groups, so small group dynamics is also a key takeaway.

\section{Paper Airplane Pitch}

This exercise involves teams of 4-5 students and takes place over two class sessions and is adapted from "Airplane Contest" [3]. Students are asked to design, fabricate, sell, and demonstrate the efficacy of their new paper airplane prototype. The constraints of the activity are that the airplane is made only from the same number of sheets of plain copier paper that there are members of the team and that the airplane must carry one U.S. dollar of coins (the number of coins is up to the team, but it must exactly add up to 100 cents). The goal of the exercise is twofold. The teams must not only design and fabricate their airplane, but perform a 2 minute sales pitch to their classmates, who will vote on which airplane they believe will fly the furthest and stay aloft the longest. The second part of the activity is for the teams to demonstrate their design by executing one throw of their airplane carrying the coins. Each team's throw is timed for loft and measured for horizontal distance. The throwing activity is best performed outside and introduces a level of uncertainty. In the first session, the exercise and goals are explained and teams are formed. Students are given time in class to work in groups on initial prototypes to serve as a team ice-breaker. Work on the sales pitch and airplane take place out of class. At the second session, teams will present their sales pitch, votes will be tallied and teams will be awarded based on the votes. At this point teams will head outdoors to have their one throw of fame. Teams that throw the farthest and aloft the longest will be awarded.

This is another fantastic team activity which takes part in class and out of class. The presentation serves as an elevator or rocket pitch of their idea and is purposely very short for students to learn about being concise and the importance of selling their design ideas, which may be more 
important than the design itself. This is also a great exercise for prototyping and creating a working prototype.

\section{Fear of Failure}

This activity is part individual exercise and part class collective in nature, where the active component becomes a collaborative reflection. The exercise was adapted from "Fear of Failure" by Yamakawa and Neck [3]. The first part of the exercise involves an individual assessment where students score themselves on nine questions (provided on a handout) designed to evaluate their risk tolerance and fear of failure on a scale of 1 to 6 . Students are then provided a sticky note and asked to compute their average score for the nine questions and write it on the sticky note. A vertical plot of the 1 to 6 scale is then drawn on a whiteboard and students are asked to approach the board and place their sticky note at the approximate location of the value on the scale. Numbers that are repeated are stacked horizontally, which creates a histogram. A discussion of the histogram begins after all students have finished placing their sticky note.

We utilize this exercise to develop an understanding of failure for each student and applying this to engineering design. Having fear that you do not know exists may inhibit your ability to design creatively and contribute to group design. The debrief of the exercise also discusses the need for awareness that fear of failure and risk tolerance vary amongst groups and countries and the impact this has on entrepreneurship. The scale represents from 1 (most tolerant) to 6 (most fearful) the assessment of an individuals fear of failure. Discussion of outliers and the distribution leads to the understanding that we don't all fear failure the same and this is important for entrepreneurship and engineering. If we are afraid of doing (action) then the hesitancy can stifle opportunity and innovation.

\section{Who's on First?}

This is a team exercise that takes place in class and follows the "Who's on First?" by Elaine Eisenman [3]. Each team of $\sim 5$ students is given the same challenge sheet which identifies the goal of filling in eight positions of a baseball team (sans the center fielder) based on 16 informational statements that are given. It is not necessary to know anything about baseball to complete the challenge. Students are given 25 minutes to complete the challenge and are asked to complete it as a team.

The challenge can be solved swiftly by students who understand decision matrices and can be completed in 15-20 minutes. In the debrief, discussion focuses on decision-making styles (Autonomous, Consultative, Joint, and Delegative) and effective leadership. This exercise is important for students to understand that decision-making style effectiveness may depend on the problem at hand, and that teams need to discuss what is the best approach for solving a problem openly and with agility. The exercise can be used with existing engineering design groups or with randomly chosen groups, regardless, teams should be solving the challenge as a team. Groups which fail to recognize the need of a matrix and become splintered (sub-groups break off) or over-analyze the problem tend to not complete the challenge and these are important takeaways to debrief in the context of decision-making styles. 


\section{Competitive Cup Stacking}

This is an exciting, hands-on exercise that follows the exercise by Erik Noyes [3]. The exercise uses 182 plastic $16 \mathrm{oz}$. cups and is a timed challenge which promotes excitement on the first day of class. Four students are chosen to create 28 cup pyramids with a 7 cup base followed by 6 until 1 cup is at the top. The student that can erect and collapse the pyramid without it falling down is the winner. Then the two fastest students are asked to choose a partner and prepare for another competition. Instead of 28 cups the pair of students are presented with 91 cups to stack (which creates a 13 cup tall pyramid). At this point the exercise gets chaotic and complicated.

Different than many of the EM exercises, creativity is not necessary in this challenge, but it provides a fun activity to metaphorically consider the concept of scaling. In the debrief, we discuss the scaling of the cup stacking from 28 cups to 91 cups and how the strategies and techniques used for 28 cups did not scale to 91 . This is important for entrepreneurs and engineers to understand, for example, the way a structure is built does not necessarily scale. Building a kitchen table versus building a bridge over a river require different processes, though both are structures. In business as well as in design the ability to understand the scaling problem can underline success by enabling growth. By not considering process scale, what worked before may not work as a business grows.

\section{How Many Uses for a Brick?}

This exercise is a divergent thinking activity that has students consider the uses of a brick beyond the function of a building material. This exercise is attributed to Suzanne Burgoyne from the University of Missouri. Students are given 1 minute to list out all the uses of a brick they can think of. Students are then asked how many people have 10 uses? 15? 20? etc... Then students are asked to volunteer novel answers. A debrief follows the discussion.

This exercise is used in the freshman engineering course during the introduction to brainstorming in the design process. In the debrief, it is stressed that the limits to your lists stem from your self-critical nature. In brainstorming, don't criticize yourself in your head, instead write your ideas down, no matter how crazy or outlandish they may be. Brainstorming is also a nonjudgmental time for a design team. Criticizing an idea early in the design process stifles creativity.

\section{Assessment Tool}

The active learning EM exercises were implemented in the freshman engineering course in Fall 2017 and Fall 2018. A survey was administered to the all 66 students enrolled in the course at the end of the Fall 2018 semester to gather assessment on the self-perceived interest and effectiveness of the EM activities. The survey contained 22 questions contained within three distinct question sets. The first set can be seen in Table 1 and asks students to evaluate their enjoyment in participating in the eight EM activities described earlier in this paper and their overall enjoyment of the EM activities. Students evaluated on a five step Likert scale which 
included $\mathrm{SD}=$ Strongly Disagree, $\mathrm{D}=$ Disagree, $\mathrm{N}=\mathrm{Neutral}, \mathrm{A}=$ Agree, and $\mathrm{SA}=$ Strongly Agree and were asked to choose one.

Table 1. Entrepreneurial Mindset activity participation enjoyment questions and evaluation scale: SD - Strongly disagree D-Disagree N-Neutral A-Agree SA-Strongly Agree.

Entrepreneurial Mindset Activities:

I enjoyed participating in the following activities:

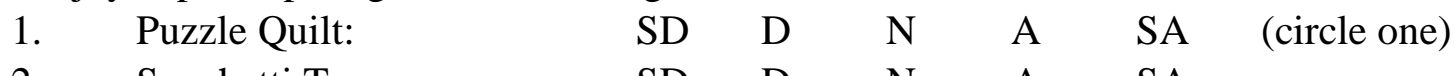

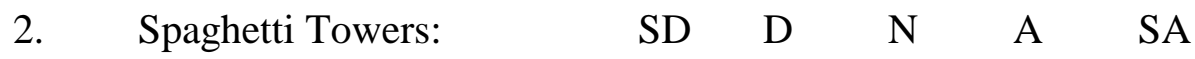

3. Crossing the River: $\quad$ SD $\quad$ D $\quad$ N $\quad$ A $\quad$ SA

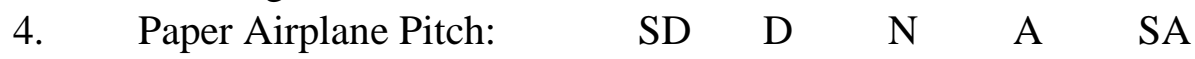

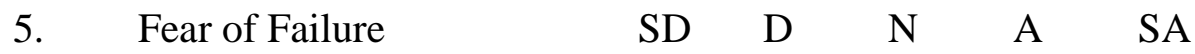

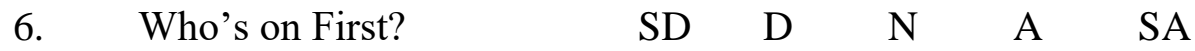

7. Competitive Cup Stacking: SD D $\quad$ N $\quad$ A $\quad$ SA

8. How Many Uses for a Brick? SD D N A SA

9. Overall, I enjoyed participating in the Entrepreneurial Mindset Activities:
SD
D N
A SA

The next set of twelve questions were designed to gage the student's understanding of specific EM competencies and are shown in Table 2. Each question was tied to specific EM activities to provide context for the question. Students again evaluated using a five step Likert scale ranging from SD=Strongly Disagree to SA=Strongly Agree. The third set consisted of a single openended question that asked for "Comments on Entrepreneurial Mindset Activities." 
Table 2. Survey questions on specific EM competencies. Evaluation scale was identical for all questions.

\begin{tabular}{|l|l|}
\hline$\#$ & SD - Strongly disagree D - Disagree N - Neutral A - Agree SA - Strongly Agree \\
\hline 10. & $\begin{array}{l}\text { Problem solving can be unstructured (quilt-like) at times and be structured (puzzle-like) } \\
\text { at times: }\end{array}$ \\
\hline 11. & $\begin{array}{l}\text { When you create an engineering design (e.g. a spaghetti tower) planning the full design } \\
\text { should come before building any prototype: }\end{array}$ \\
\hline 12. & $\begin{array}{l}\text { Engineers who create a design need to be able to convince/sell why their design is } \\
\text { awesome to co-workers, managers, and potential customers: }\end{array}$ \\
\hline 13. & $\begin{array}{l}\text { The Cup Stacking competition had you work in teams on stacks of increasing scales. In } \\
\text { engineering, problems of different scales are commonly found, where processes/designs } \\
\text { may need to be adapted based on needs: }\end{array}$ \\
\hline 14. & $\begin{array}{l}\text { Strong leadership plays a critical role in solving challenges resulting from limited } \\
\text { resources and time constraints (e.g. crossing the volleyball courts): }\end{array}$ \\
\hline 15. & Understanding your own fear of failure can help you be a better engineer: \\
\hline 16. & $\begin{array}{l}\text { The approach to solving complicated problems (e.g. "Who's on First") can impact both } \\
\text { process and outcomes: }\end{array}$ \\
\hline 17. & $\begin{array}{l}\text { When brainstorming, critical judgement can slow down or stop the creative process (e.g. } \\
\text { How many uses for a brick?): }\end{array}$ \\
\hline 18. & $\begin{array}{l}\text { Learning from small experiments and trials can produce better solutions (e.g. making } \\
\text { mockups): }\end{array}$ \\
\hline 19. & $\begin{array}{l}\text { The entrepreneurial mindset activities helped me understand how to deal with } \\
\text { uncertainty in design: }\end{array}$ \\
\hline 20. & $\begin{array}{l}\text { The entrepreneurial mindset activities helped me generate creative solutions with } \\
\text { limited resources: }\end{array}$ \\
\hline 21. & $\begin{array}{l}\text { The entrepreneurial mindset activities helped me understand how group dynamics and } \\
\text { leader behavior play a critical role in defining and solving challenges. }\end{array}$ \\
\hline
\end{tabular}

\section{Results and Discussion}

Data was compiled from the surveys and the SD to SA scale was converted to a numeric scale using $\mathrm{SD}=1, \mathrm{D}=2, \mathrm{~N}=3, \mathrm{~A}=4, \mathrm{SA}=5$. Average scores were computed for each question in the survey except the open comment question. Average scores for the first nine questions which focused on EM activity participation enjoyment are presented in Figure 1. The data indicates from Question 9 (highlighted orange in Figure 1) that students overall agreed the EM activities were enjoyable to participate in. Individual EM activity scores varied from 3.56 (Question 5) to 4.35 (Question 3). All of the exercises which were highly active (i.e. students moving around the room, from room to room, or working in teams) scored above 4.0 (Questions $1,2,3,4$, and 7). It is difficult to discern if this is due to the active nature of these exercises, but this is an exciting trend to report. 
SA 5.0

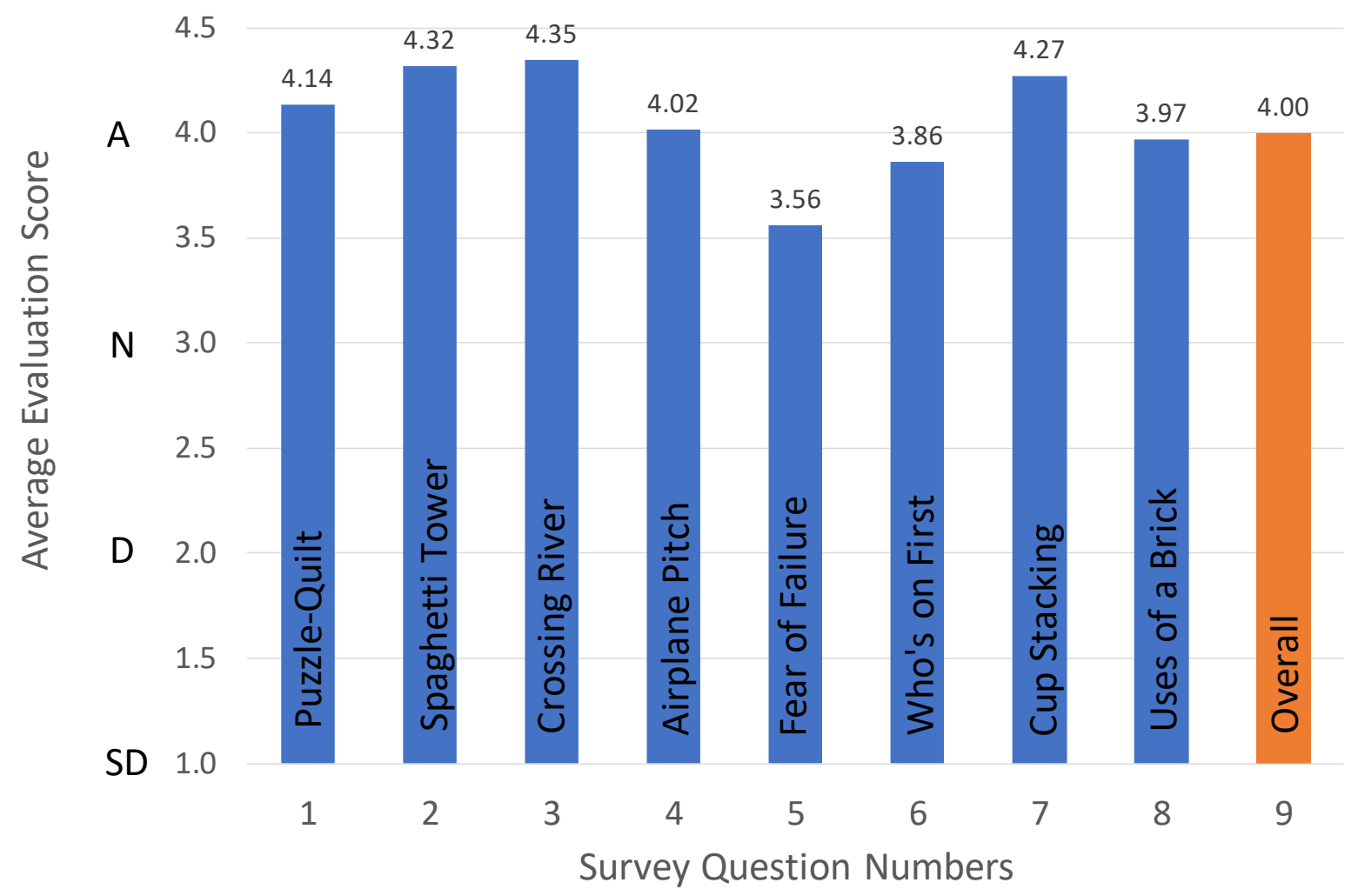

Figure 1. Average evaluation scores for survey questions 1-9 focused on EM activity participation enjoyment. Overall enjoyment (Question 9) is highlighted in orange. The scale of 1 to 5 reflects the evaluation scale of SD (Strongly Disagree) to SA (Strongly Agree).

The second set of questions focused on the EM competencies in the context of the EM exercises and required students to consider the relationship to engineering design-related outcomes. The average scores for survey questions 10-21 can be found in Figure 2. The average data shows that the EM competencies surveyed were all at or above the agreed value of 4.0. The data for question 11 is noted to be lower than 4.0 and is due to the nature of the survey question. The question was designed to be answered with a false-positive (SD) if the students understood the EM competency. Since this was the only question with this form of response, all students may not have fully understood the question leading to many SA answers from the survey. The average calculated for questions 10 and 12-21 (excluding question 11) is 4.20, which gives a strong indication that students understood the EM competencies and design related questions after participating in the EM exercises. The design related questions (19-21) are highlighted green in Figure 2 and show that the EM exercises aided the students in the creative design and teamwork aspects of the freshman engineering course. It is important to note that the effectiveness of the active EM exercises in teaching EM competencies cannot be drawn from this data since an alternative method for teaching the EM competencies has not been used in this course. 
SA 5.0

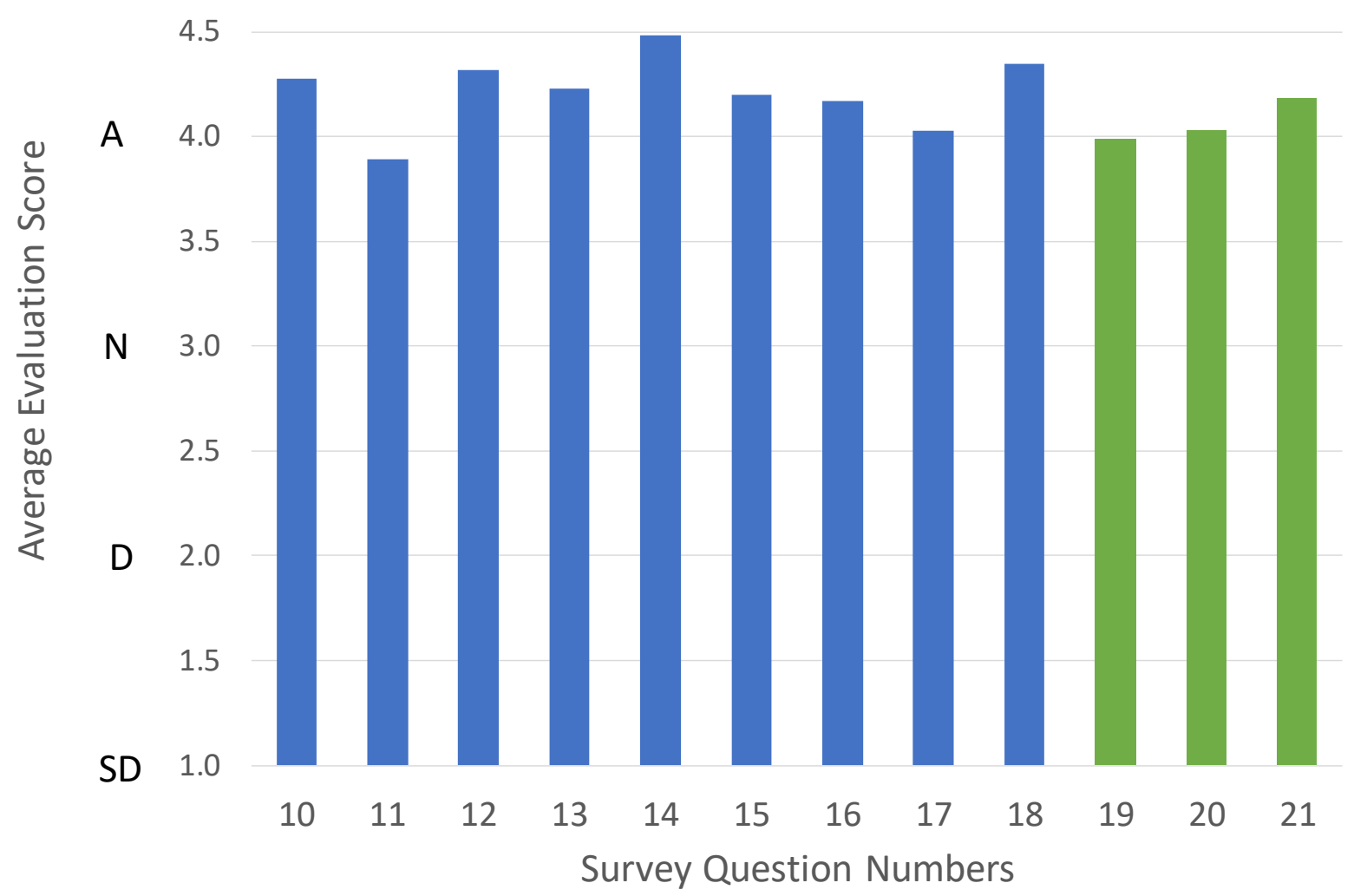

Figure 2. Average evaluation scores for survey questions 10-21 focused on EM competencies and design. Design related questions (10-12) are highlighted green. The scale of 1 to 5 reflects the evaluation scale of SD (Strongly Disagree) to SA (Strongly Agree).

Open-ended comments on the EM exercises from student surveys provided promising insight to their success in the course:

"They gave me a good preview at how it will be to solve problems as an engineer." "Overall the activities were great! Fun an they taught many lessons."

"All of them were fun and interesting once we found out why we did them, what point they were meant to prove."

"Overall I really enjoyed them and they were fun hands on learning devices!"

"Fun and require quick thinking at times." 
"I very much enjoyed the activities and it is great that we have them because it makes me more engaged in class."

"The variety of activities that were performed in class were all relatable and beneficial to the engineering process and development of learning."

"They were fun and gave good experiences to learn from."

"They were fun and challenging."

"Loved the activities."

"They were really fun and at the same time helped us learn."

"Some of them seemed like a waste of time at first but it helped us understand some of the basic principles of engineering."

And also provided feedback that improvements are still needed:

"They weren't very useful in changing my mindset on any of the topics."

"I liked all of them but the crossing the river one."

"They were not explained so that the class could understand what the objective was. They were thus very confusing and I don't believe they helped us do anything."

Not all students were found to be excited about the EM exercises, though the open comments that provided positive feedback far out-numbered the constructive feedback from the students. This correlates to the average scores recorded from the survey questions that students enjoyed the active EM exercises and gained insight into the EM competencies.

\section{Conclusions}

In this paper, active-learning based EM exercises were introduced to a first semester freshman engineering course. The exercises were dispersed throughout the semester and were related to EM competencies. Data from post-semester surveys of the course students indicate the activelearning based EM exercises were well-received by the students on average. Results from the surveys also show that EM competencies addressed by the exercises were found to be processed by the students positively. Also, survey data indicates the use of the EM exercises was also found to positively affect creative design and teamwork aspects of the course. Open comments 
from students in surveys correlated with the survey data that students were excited about the exercises and found them to be an effective learning method.

\section{References}

[1] V.E. Goodrich and L.H. McWilliams, "Implementation of a Flotation Platform Project for a First-Year Engineering, Project-Based Course". Proceedings of the 2016 ASEE conference and exposition.

[2] C. Wang. "Teaching Entrepreneurial Mindset in a first-year introduction to engineering course". Proceedings of the 2017 ASEE conference and exposition.

[3] Neck, H.M., Greene, P.G., Brush, C.G. 2014. Teaching Entrepreneurship: A Practice-Based Approach. Northampton, MA: Edward Elgar Publishing.

[4] Accessed from https://www.tomwujec.com/marshmallowchallenge

[5] D. Raviv. "Hands-on Activities for Innovative Problem Solving". Proceedings of the 2004 ASEE Conference and Exposition. 